\title{
Aydın Ilii ikinci Ürün Pamukta (Gossypium hirsutum L.) Farklı Azot Dozlarının Verim, Verim Komponentleri ve Lif Kalite Özellikleri Üzerine Etkisi
}

\author{
Sergül ÇOPUL ${ }^{* 1}$, ibrahim GENÇSOYLU \\ ${ }^{1}$ Nazilli Pamuk Araştırma Enstitüsü Müdürlüğü, Nazilli, Aydın \\ ${ }^{2}$ Aydın Adnan Menderes Üniversitesi, Ziraat Fakültesi, Bitki Korumu Bölümü, Aydın
}

Öz: Bu çalışma, 2016 ve 2017 yıllarında, ikinci ürün pamuk üretim sezonunda, farklı azot dozlarının (0, 70, 140 ve $210 \mathrm{~kg}$ $\mathrm{N} / \mathrm{ha}$ ); verim, verim komponentleri ve lif kalite özellikleri üzerine etkisini saptamak amacıyla Nazilli Pamuk Araştırma Enstitüsü deneme arazisinde yürütülmüştür. Denemede materyal olarak 4 farklı pamuk çeşidi (Özbek 105, Gloria, Julia ve Lydia) kullanıımışıı. Çalışmada, azot dozu miktarındaki artışın, kütlü pamuk verimini belirli bir noktaya kadar arttırdığı belirlenmiştir. Yapılan istatistiksel analizler sonucunda, kütlü pamuk verimi bakımından en ekonomik azot dozunun, $150 \mathrm{~kg}$ $\mathrm{N} /$ ha olduğu belirlenmiştir. Azot dozu miktarındaki artış ile 100 tohum ağırlı̆̆ı (g), bitki boyu (cm), koza sayısı (adet/bitki), lif inceliği (mic) ve lif uzunluğu $(\mathrm{mm})$ değerlerinin arttığı; çırçır randımanının (\%) ise azaldığı belirlenmiştir. Ayrıca, azot dozlarının, lif kopma dayanıkılığı (g/tex) ve üniformite indeksi (\%) değerleri üzerinde ise istatistiksel açıdan önemli bir etkisinin olmadığı tespit edilmiştir.

Anahtar Kelimeler: gübreleme, kütlü pamuk verimi, koza, çırçır randımanı, lif

The Effects of Different Doses of Nitrogen Fertilizer on Yield, Yield Components and Fiber Quality Properties in Second Crop Cotton in Aydın Province, TURKEY

Abstract: This study was conducted at the Experimental Area of Nazilli Cotton Researh Institute in second crop cotton season in years, 20162017. It was aimed to determine different doses of nitrogen fertilizer $(0,70,140$ ve $210 \mathrm{~kg} \mathrm{~N} / \mathrm{ha}$ ) on yield, yield components and fiber quality parameters. Özbek 105, Gloria, Julia and Lydia cotton varieties were used as cotton varieties. In our study, it was determined that the increase at the amount of nitrogen dose increased the yield of seed cotton to a certain level. It was determined that the most economical nitrogen dose used for all cotton varieties where the highest density cotton yields were obtained, was $150 \mathrm{~kg} N / \mathrm{ha}$ dose. In addition, an increase at the amount of nitrogen increased 100 seed weight (g), plant height (cm), the number of boll per plant, fiber thinness (mic) and fiber length (mm); decreased ginning outturn (\%). However, nitrogen doses did not cause significant difference in fiber strength ( $g /$ tex) and fiber uniformity index (\%).

Keywords: Fertilization, cotton seed yield, boll, ginning percentage, fiber

\section{Gíriş}

Pamuk (Gossypium hirsitum L.), Dünya'da ve Türkiye'de önemli bir tekstil ham maddesidir. Ülkemizde pamuk üretiminin yoğun olarak yapıldığı üç bölge olan Güneydoğu Anadolu, Ege ve Akdeniz Bölgelerinde, birinci ürün ve ikinci ürün pamuk olmak üzere yaklaşık olarak 5.006 .843 ha alanda pamuk ekimi yapılmakta olup, bu alanın 1.073.857 dekarı Ege Bölgesi'nde yer almaktadır (Anonim, 2018).

Pamuk bitkisi, her türlü toprakta yetiştirilebilir. Ancak toprağın fiziksel ve kimyasal özellikleri ile biyolojik faaliyetler bakımından durumu, pamuk üretiminde verim ve kaliteyi önemli oranda etkilemektedir (Berger, 1969).

Pamuk üretiminde yapılan gübreleme kapsamında bitki besin maddeleri, hem topraktan hem de yapraktan uygulanmaktadır. Azotlu gübreler, pamuk üretiminde en yaygın şekilde kullanılan bitki besin öğesidir (Weir ve ark., 1996).

Bitki besin elementi olarak mutlak gerekli olan azotlu gübrelerin, noksan olmaları durumunda ortaya çıkabilecek olan olumsuz etkilerin yanı sıra bu gübrelerin, aşırı dozda kullanılmaları sonucunda da birtakım olumsuz etkiler ortaya çıkabilmektedir (Mart, 2005).
Azot eksikliği durumunda, kozalar alt dallarda oluşmakta, koza sayısı ve koza iriliği azalmakta, bitki veriminde büyük kayıplar meydana gelmektedir (Radin ve Mauney, 1986; Gerik ve ark., 1996). Yüksek dozdaki azot uygulamaları ise vegetatif gelişmeyi arttırarak hem bitkide olgunlaşmayı geciktirmekte hem de daha çok çiçek dökümüne neden olarak verim kayıplarına neden olmaktadır (Aydemir, 1968). Ayrıca, uygulanan azot dozundaki artış, çırçır randımanını olumsuz yönde etkilemektedir (Emiroğlu, 1970).

Çalışma, pamukta uygulanan azot dozlarının, verim, verim özellikleri ve bazı lif kalite parametreleri üzerindeki etkilerini belirlemek amacıyla 2016-2017 yılları arasında, ikinci ürün pamuk üretim sezonunda yürütülmüştür.

*Sorumlu Yazar: sergulcopul@hotmail.com. Bu çalışma doktora tez ürünüdür ve Aydın Adnan Menderes Üniversitesi Bilimsel Araştırma Projeleri Komisyonu (Proje No: ZRF-15072) ve Tarımsal Araştırmalar ve Politikalar Genel Müdürlüğü (TAGEM) (Proje No: TAGEM/BSAD/16/1/01/13) tarafından desteklenmiştir. Geliş Tarihi: 17 Temmuz 2020

Kabul Tarihi: 1 Kasım 2020 


\section{MATERYAL VE YÖNTEM Materyal}

Araştırma, Nazilli Pamuk Araştırma Enstitüsü Müdürlüğü'ne ait 7 dekar büyüklüğündeki bir deneme arazisinde, 2016 ve 2017 yıllarında ikinci ürün pamuk üretim sezonu boyunca yürütülmüştür. Araştırmada, bölgede ikinci ürün pamuk tarımında, üreticiler tarafından yoğun olarak kullanılan 4 farklı pamuk çeşidi (Özbek 105, Gloria, Julia ve Lydia) kullanılmış ve 4 farklı $N$ dozu (0, 70, 140 ve $210 \mathrm{~kg} \mathrm{~N} / \mathrm{ha}$ ) uygulanmıştır. Ayrıca, ekim öncesinde yapılan toprak analizleri doğrultusunda, tüm parsellere, triple süper fosfat (TSP) ve potasyum sülfat (PS) gübreleri, ekim öncesinde taban gübresi olarak uygulanmıştır (Çizelge 1).

Yöntem

Toprak Örneklerinin Alınması, Pamuk Ekiminin Yapılması, Gübre Uygulamaları ve Diğer Kültürel İşlemler

Deneme arazisindeki toprağın, fiziksel ve kimyasal özelliklerini belirlemek için, pamuk ekiminden yaklaşık 1 ay önce (26/04/2016 ve 24/04/2017 tarihlerinde), Jackson (1967) tarafından bildirilen yönteme uygun olarak 0-30 cm toprak derinliğinden, toprak örnekleri alınmıştır. Toprak örneklerinin analizi, Aydın Adnan Menderes Üniversitesi Ziraat Fakültesi Toprak ve Bitki Besleme Bölümü Laboratuvarı'nda yapılmış ve toprağın fiziksel ve kimyasal özellikleri belirlenmiştir.

Araştırma, tesadüf bloklarında bölünmüş parseller deneme desenine göre dört tekerrürlü olarak ve her bir tekerrürün parsel büyüklükleri 8 sıra x 4 çeşit x 0,7 m (sıra arası) x $12 \mathrm{~m}$ (sıra uzunluğu) $=268,8 \mathrm{~m}^{2}$ olacak şekilde Nazilli Pamuk Araştırma Enstitüsü Müdürlüğü deneme arazisinde yürütülmüştür. Araştırmada, ana parselleri, azot dozları; alt parselleri ise pamuk çeşitleri oluşturmuştur. Araştırmada kullanılan azot dozlarının, \%50'si amonyum sülfat (AS) (\%21 N) formunda taban gübresi olarak ekim öncesi dönemde; geri kalan \%50'si ise amonyum nitrat (AN) (\%33 N) formunda üst gübre olarak 1.sulama öncesinde elle serpilerek uygulanmıştır. Araştırmada, kültürel işlemler zamanında ve usulüne uygun olarak yapılmıştır. Denemede, 12 'şer m uzunluğunda, 8'er sıradan oluşan her alt parselin ortasında yer alan 4 sıra, tek seferde ve elle hasat edilmiştir. Hasat, 2016 yılında 16 Kasım ve 2017 yılında 8 Kasım tarihinde yapılmıştır.

\section{Verim ve Verim Komponentlerinin Belirlenmesi}

Araştırmada, verim ve verim unsurları kapsamında; kütlü pamuk verimi $(\mathrm{kg} / \mathrm{da}), 100$ tohum ağırlığı $(\mathrm{g})$, bitki boyu (cm), koza sayısı (adet/bitki) ve çırçır randımanı (\%) özellikleri ile ilgili analizler aşağıda belirtilen şekillerde yapılmıştır.

\section{Kütlü Pamuk Verimi (kg/da):}

Hasatta, 8'er sıradan oluşan her alt parselin ortasında yer alan 4 sıradan toplanan kütlü pamuk miktarları g cinsinden tartılmış olup, dekara kütlü pamuk verimi kg olarak hesaplanmıştır.

100 tohum ağırlığı (g): Her alt parselin ortasında yer alan 4 sıradan alınmış olan kütlü pamuğun çırçırlanması ile elde edilmiş tohumlardan, rastgele 100 'er adet seçilmiş, 0,01 g duyarlı terazide tartılmış ve tekerrürlerden elde edilen değerlerin ortalamaları alınmıştır.

Bitki Boyu (cm): Her alt parselin ortasında yer alan 4 sıradan rastgele seçilen 10 bitkinin, kotiledon yapraklarından üst büyüme konisine kadar olan uzaklık cm olarak ölçülmüş, daha sonra bu değerlerin ortalaması alınmıştır.

Koza Sayısı (adet/bitki): Her alt parselin ortasında yer alan 4 sıradan alınan rastgele seçilen 10 bitkinin, hasat esnasında açmış veya toplanabilecek durumda olan kozaları sayılmış ve ortalaması alınmıştır.

Çırçır Randımanı (\%): Her alt parselin ortasında yer alan 4 sıradan alınan 50 adet kozaya ait kütlü pamuk, rollergin çırçır makinasından geçirilmiş, lif ve tohum (çiğit) olmak üzere ayrılarak tartılmış ve aşağıdaki formül yardımıyla hesaplanmıştır.

Çırçır Randımanı = [Lif Ağırlığı (g)/(Tohum Ağırlığı (g) + Lif Ağırlığı (g))] x 100

\section{Lif Kalite Değerlerinin Belirlenmesi}

Araştırmada, her alt parselin ortasında yer alan 4 sıradan olmak üzere 40 adet kütlü koza örneği alınmış ve kütlü koza örnekleri, Rollergin çırçır makinasında çırçırlanmıştır.

Çizelge 1. Araştırmada kullanılan gübrelerin içeriği ve uygulanma dönemleri

\begin{tabular}{|c|c|c|c|c|}
\hline \multirow{2}{*}{ Gübreler } & \multirow{2}{*}{ Gübrelerin İçeriği } & \multirow{2}{*}{$\begin{array}{l}\text { Gübrelerin Uygulanma } \\
\text { Dönemi }\end{array}$} & \multicolumn{2}{|c|}{ Gübrelerin Uygulanma Tarihleri } \\
\hline & & & 2016 Yilı & 2017 Yılı \\
\hline Amonyum Sülfat & Azot (N): \%21 Kükürt (S): \%24 & $\begin{array}{l}\text { Ekim öncesinde taban } \\
\text { gübresi olarak }\end{array}$ & 9 Haziran & 4 Haziran \\
\hline Amonyum Nitrat & Azot :\%33 & $\begin{array}{l}\text { 1.sulama öncesinde üst } \\
\text { gübre olarak }\end{array}$ & 22 Temmuz & 12 Temmuz \\
\hline Potasyum Sülfat & $\begin{array}{l}\text { Potasyum Oksit }\left(\mathrm{K}_{2} \mathrm{O}\right): \% 50 \\
\text { Kükürt }(\mathrm{S}): \% 16-20\end{array}$ & $\begin{array}{l}\text { Ekim öncesinde taban } \\
\text { gübresi olarak }\end{array}$ & 3 Haziran & 29 Mayıs \\
\hline Triple Süper Fosfat & Fosfor Pentaoksit $\left(\mathrm{P}_{2} \mathrm{O}_{5}\right)$ : \%42 & $\begin{array}{l}\text { Ekim öncesinde taban } \\
\text { gübresi olarak }\end{array}$ & 3 Haziran & 29 Mayıs \\
\hline
\end{tabular}


Çırçırlama işlemi sonucunda elde edilen elyafların; lif inceliği (mic), lif uzunluğu (mm), lif kopma dayanıklılığı (g/tex) ve üniformite indeksi (\%) analizleri, Nazilli Pamuk Araştırma Enstitüsü Müdürlüğü Lif Analiz Laboratuvarı'nda HVI cihazında yapılmıştır.

\section{İstatistiksel Değerlendirmeler}

Farklı azot dozlarının; verim, verim komponentleri ve lif kalite parametreleri üzerindeki etkilerini belirleyebilmek için, JUMP 13 istatistik programında, tesadüf blokları deneme desenine göre varyans analizi uygulanmış olup, ortalamaların karşılaştırılmasında LSD testinden yararlanılmıştır $(p<0.05)$. Denemeler için, dört çeşit, dört farklı azot dozu ve dört tekerrürlü olarak Tesadüf Bloklarında Bölünmüş Parseller Deneme desenine göre kurulmuş ve 2 yıl sürdürülmüş bir deneme için uygun JUMP modeli uygulanmıştır.

\section{BULGULAR VE TARTIŞMA}

Pamuk çeşitlerinde farklı azot dozlarında tespit edilen verim ve verim unsurlarına ait değerlere ilişkin yapılan varyans analizi sonuçlarına göre; kütlü pamuk verimi $(\mathrm{kg} / \mathrm{da})$, çırçır randımanı (\%), 100 tohum ağırlığı $(\mathrm{g})$, bitki boyu $(\mathrm{cm})$ ve koza sayısı (adet/bitki) değerleri bakımından, çeşitler ve
ÇOPUL S, GENÇSOYLU i azot dozları arasındaki farkın istatistiksel açıdan önemli düzeyde $(p<0.05)$ olmuştur (Çizelge 2$)$.

İki yıllık ortalama kütlü pamuk verimi değerleri, azot dozları bakımından incelendiğinde; uygulanan tüm azot dozlarında, en yüksek kütlü pamuk verimleri, Özbek 105 (290.51, $336.01, \quad 355.47$ ve $361.80 \mathrm{~kg} / \mathrm{da}$ ) pamuk çeşidinde belirlenmiş, bunu sırasıyla Lydia (284.90, 329.43, 349.00 ve $337.80 \mathrm{~kg} / \mathrm{da}$ ) ve Gloria $(281.25,316.67,336.38$ ve 326.38 $\mathrm{kg} / \mathrm{da}$ ) pamuk çeşitleri izlemiş; en düşük kütlü pamuk verimi değerleri ise Julia (249.00, 257.22, 302.38 ve 289.62 kg/da) pamuk çeşidinde saptanmıştır. Kütlü pamuk verimi değerleri, pamuk çeşitleri bakımından incelendiğinde tüm pamuk çeşitlerinde en yüksek kütlü pamuk verimleri, 140 ve $210 \mathrm{~kg} \mathrm{~N} /$ ha azot dozlarında; en düşük kütlü pamuk verimi değerleri ise $0 \mathrm{~kg} \mathrm{~N} / \mathrm{ha}$ azot dozunda tespit edilmiştir (Çizelge 3).

Çalışmada, kütlü pamuk veriminin, $140 \mathrm{~kg} \mathrm{~N} / \mathrm{ha}$ azot dozuna kadar arttığı, $210 \mathrm{~kg} \mathrm{~N} /$ ha azot dozunda ise kütlü pamuk verimi değerlerinin azalmaya başladığı saptanmıştır. Berberoğlu ve Karaaltın (2001), Toklu (2003), Ge ve ark. (2003), Karademir ve ark. (2005), Yolcu (2009), Parajulee ve ark. (2016), Anusha ve ark. (2017), Li ve ark. (2017) ve Win ve ark. (2017) tarafından yürütülmüş önceki çalışmalarda

Çizelge 2. Pamuk çeşitlerinde farklı azot dozlarında tespit edilen verim ve verim komponentlerine ilişkin varyans analizi sonuçları

\begin{tabular}{|c|c|c|c|c|c|c|}
\hline Varyasyon Kaynağı & SD & $\begin{array}{l}\text { Kütlü Pamuk } \\
\text { Verimi }\end{array}$ & $\begin{array}{l}\text { Çırçır } \\
\text { Randımanı }\end{array}$ & $\begin{array}{l}\text { Yüz Tohum } \\
\text { Ağırlığı }\end{array}$ & Bitki Boyu & Koza Sayısı \\
\hline Yll & 1 & $11598.026^{*}$ & $17.59728^{*}$ & 0.018288 & $473.5395^{*}$ & 1294.39* \\
\hline Tekerrür [Yıl] & 6 & 343.29 & 1.70699 & 0.093113 & 96.2882 & 0.206578 \\
\hline Çeşit & 3 & $23038.8317^{*}$ & $48.33548 *$ & $9.00154 *$ & $919.5887^{*}$ & $52.232567 *$ \\
\hline Yıl x Çeşit & 3 & 761.205 & $2.25452 *$ & 0.00524 & 26.4365 & $1.316717^{*}$ \\
\hline Azot Dozları & 3 & $22626.2477^{*}$ & $44.74716^{*}$ & $8.453374^{*}$ & $5221.011^{*}$ & $53.116867 *$ \\
\hline Yıl x Azot Dozları & 3 & 365.1723 & $11.59513^{*}$ & 0.004974 & 19.4227 & $5.63915^{*}$ \\
\hline Çeşit x Azot Dozları & 9 & $603.8113^{*}$ & 0.39163 & 0.021627 & 8.2492 & 0.327644 \\
\hline Yıl x Çeşit x Azot Dozları & 9 & 313.2668 & 0.36336 & 0.006059 & 11.7937 & 0.170978 \\
\hline Hata & 90 & 294.04 & 0.77612 & 0.06713 & 18.386 & 0.3295 \\
\hline Cv (\%) & & 5.48 & 2.17 & 2.48 & 4.48 & 5.51 \\
\hline
\end{tabular}

$(*)$ : 0.05 düzeyinde önemli fark bulunmaktadır.

Çizelge 3. Farklı azot dozları ve pamuk çeşitlerinde ortalama kütlü pamuk verimi değerleri*

\begin{tabular}{llllll}
\hline $\begin{array}{l}\text { Azot Dozları } \\
\text { (kg N/ha) }\end{array}$ & Özbek105 & Gloria & $\begin{array}{c}\text { Çeşitler } \\
\text { Julia }\end{array}$ & Lydia & Azot Dozları Ort. \\
\hline $\mathbf{0}$ & $290.51 \mathrm{Ac}$ & $281.25 \mathrm{Ac}$ & $249.00 \mathrm{Bb}$ & $284.90 \mathrm{Ac}$ & $276.41 \mathrm{c}$ \\
$\mathbf{7 0}$ & $336.01 \mathrm{Ab}$ & $316.67 \mathrm{Ab}$ & $257.22 \mathrm{Bb}$ & $329.43 \mathrm{Ab}$ & $309.83 \mathrm{~b}$ \\
$\mathbf{1 4 0}$ & $355.47 \mathrm{Aab}$ & $336.38 \mathrm{Aa}$ & $302.38 \mathrm{Ba}$ & $349.00 \mathrm{Aa}$ & $335.81 \mathrm{a}$ \\
$\mathbf{2 1 0}$ & $361.80 \mathrm{Aa}$ & $326.38 \mathrm{Bab}$ & $289.62 \mathrm{Ca}$ & $337.80 \mathrm{ABab}$ & $328.90 \mathrm{a}$ \\
Çeşit Ort. & $335.95 \mathrm{~A}$ & $315.17 \mathrm{C}$ & $274.55 \mathrm{D}$ & $325.28 \mathrm{~B}$ & \\
LSD & & & & \\
\hline
\end{tabular}

*íki yılın ortalama değerleri alınmıştır. Aynı harfle gösterilen ortalamalar arasında, LSD testine göre ( $p<0.05)$ istatistiksel olarak fark yoktur. Küçük harfler, aynı sütundaki ortalamalar arasındaki farklılıkları göstermektedir $(p<0.05)$.

Büyük harfler, aynı satırdaki ortalamalar arasındaki farklııkları göstermektedir $(p<0.05)$. 
da, uygulanan azot dozu miktarındaki artış ile birlikte kütlü pamuk verimindeki artışın, optimum azot dozuna kadar sürdüğü bildirilmiştir. Optimum azot dozunun üzerindeki uygulamalarda kütlü pamuk verimindeki azalış; uygulanan azot dozu miktarındaki artışa bağı olarak pamuk bitkisinin alt kısımlarındaki meyve dallarında hasat edilebilir koza sayısı azalması ile kütlü pamuk verimindeki artışın, belirli bir azot dozuna kadar devam etmesinden yani verimdeki artışın, sınırlı olmasından kaynaklanmaktadır (Boquet ve ark., 1993).

Çırçır randımanı değerleri, azot dozları bakımından incelendiğinde; uygulanan tüm $\mathrm{N}$ dozlarında, en yüksek çırçır randımanı değerleri, Gloria ve Julia pamuk çeşitlerinde; en düşük çırçır randımanları ise Özbek 105 pamuk çeşidinde belirlenmiştir. Çırçır randımanı değerleri, pamuk çeşitleri bakımından incelendiğinde ise kullanılan tüm pamuk çeşitlerinde en yüksek çırçır randımanı değerleri, $0 \mathrm{~kg} \mathrm{~N} / \mathrm{ha}$ azot dozunda, en düşük çırçır randımanları ise $210 \mathrm{~kg} \mathrm{~N} / \mathrm{ha}$ azot dozunda tespit edilmiştir (Çizelge 4)

Çalışmamızda, azot dozlarının, çırçır randımanı (\%) değerleri üzerinde etkili olduğu ve uygulanan azot dozu miktarındaki artış ile birlikte, çırçır randımanı değerlerinin azaldığı tespit edilmiştir. Emiroğlu (1970), Şenel (1980), Şahin ve ark.

Çizelge 4. Farklı azot dozları ve pamuk çeşitlerinde ortalama çırçır randımanı değerleri*

\begin{tabular}{llllll}
\hline $\begin{array}{l}\text { Azot Dozları } \\
\text { (kg N/ha) }\end{array}$ & Özbek105 & Gloria & Julia & Lydia & Azot Dozları Ort. \\
\hline $\mathbf{0}$ & $39.94 \mathrm{Ba}$ & $43.06 \mathrm{Aa}$ & $42.81 \mathrm{Aa}$ & $41.91 \mathrm{Aa}$ & $41.93 \mathrm{a}$ \\
$\mathbf{7 0}$ & $39.79 \mathrm{Ba}$ & $42.11 \mathrm{Aab}$ & $41.91 \mathrm{Aab}$ & $41.60 \mathrm{Aa}$ & $41.36 \mathrm{~b}$ \\
$\mathbf{1 4 0}$ & $38.33 \mathrm{Cb}$ & $41.41 \mathrm{Ab}$ & $40.61 \mathrm{ABbc}$ & $40.21 \mathrm{Bb}$ & $40.14 \mathrm{C}$ \\
$\mathbf{2 1 0}$ & $37.61 \mathrm{Bb}$ & $40.10 \mathrm{Ac}$ & $39.98 \mathrm{Ac}$ & $39.55 \mathrm{Ab}$ & $39.31 \mathrm{~d}$ \\
Çeşit Ort. & $38.92 \mathrm{C}$ & $41.67 \mathrm{~A}$ & $41.33 \mathrm{~A}$ & $40.82 \mathrm{~B}$ & \\
LSD $_{(0,05)}$ & 0.88 & & & & \\
\hline
\end{tabular}

*iki yılın ortalama değerleri alınmıştır. Aynı harfle gösterilen ortalamalar arasında, LSD testine göre ( $p<0.05)$ istatistiksel olarak fark yoktur. Küçük harfler, aynı sütundaki ortalamalar arasındaki farklılıkları göstermektedir $(p<0.05)$.

Büyük harfler, aynı satırdaki ortalamalar arasındaki farklılıkları göstermektedir $(p<0.05)$.

Çizelge 5. Farklı azot dozları ve pamuk çeşitlerinde ortalama 100 tohum ağırlığı değerleri*

\begin{tabular}{llllll}
\hline $\begin{array}{l}\text { Azot Dozları } \\
\text { (kg N/ha) }\end{array}$ & Özbek105 & Gloria & Julia & Lydia & Azot Dozları Ort. \\
\hline $\mathbf{0}$ & $10.13 \mathrm{Ad}$ & $9.50 \mathrm{Bc}$ & $9.12 \mathrm{Cd}$ & $10.34 \mathrm{Ac}$ & $9.77 \mathrm{~d}$ \\
$\mathbf{7 0}$ & $10.63 \mathrm{Ac}$ & $10.10 \mathrm{Bb}$ & $9.68 \mathrm{Cc}$ & $10.75 \mathrm{Ab}$ & $10.29 \mathrm{c}$ \\
$\mathbf{1 4 0}$ & $11.07 \mathrm{Ab}$ & $10.54 \mathrm{Ba}$ & $9.98 \mathrm{Cb}$ & $11.20 \mathrm{Aa}$ & $10.70 \mathrm{~b}$ \\
$\mathbf{2 1 0}$ & $11.29 \mathrm{Aa}$ & $10.79 \mathrm{Ba}$ & $10.30 \mathrm{Ca}$ & $11.41 \mathrm{Aa}$ & $10.95 \mathrm{a}$ \\
Çeşit Ort. & $10.78 \mathrm{~B}$ & $10.23 \mathrm{C}$ & $9.77 \mathrm{D}$ & $10.93 \mathrm{~A}$ & \\
LSD $_{(0,05)}$ & 0.26 & & & & \\
\hline
\end{tabular}

*iki yılın ortalama değerleri alınmıştır. Aynı harfle gösterilen ortalamalar arasında, LSD testine göre ( $p<0.05)$ istatistiksel olarak fark yoktur. Küçük harfler, aynı sütundaki ortalamalar arasındaki farklılıkları göstermektedir $(p<0.05)$.

Büyük harfler, aynı satırdaki ortalamalar arasındaki farklılıkları göstermektedir $(p<0.05)$. 
bulunmaktadır. Çalışmamızda, azot dozu miktarındaki artış, çırçır randımanı değerlerini azaltmış; 100 tohum ağırlığı değerlerini ise arttırmıştır. Azot dozu miktarındaki artışın, çırçır randımanı ve tohum ağırlığı değerleri üzerindeki etkisinin farklı olmasına, bu iki değer arasındaki negatif yönlü ilişkinin etkisi olabilir. Nitekim, Kılıç (2008) tarafından yürütülmüş bir çalışmada, 100 tohum ağırlığı yönünden yüksek değerlere sahip olan STV-373 ve STV-453 pamuk çeşitlerinin, çırçır randımanı yönünden ise düşük değerlere sahip oldukları ve 100 tohum ağırlığı ile çırçır randımanı arasındaki negatif yönlü bir ilişki olduğu bildirilmiştir.

Bitki boyu değerleri, azot dozları bakımından incelendiğinde; tüm $\mathrm{N}$ dozlarında, en yüksek bitki boyları, Özbek 105 ve Lydia; en düşük bitki boyları ise Julia pamuk çeşidinde saptanmıştır. Bitki boyu değerleri, pamuk çeşitleri bakımından incelendiğinde ise tüm pamuk çeşitlerinde en yüksek bitki boyları, 140 ve $210 \mathrm{~kg} \mathrm{~N} /$ ha azot dozlarında; en düşük bitki boyları ise $0 \mathrm{~kg} \mathrm{~N} / \mathrm{ha}$ azot dozunda tespit edilmiştir (Çizelge 6).

Altınkaya (2009), Gadhiya ve ark. (2009), Yolcu (2009), Hakoomat ve Raheel (2011), Cevheri (2016), Durkal (2017) ve Win ve ark. (2017) tarafından önceki yürütülmüş çalışmalarda, azot dozundaki artışın, bitki boyu değerlerinin de arttırdığı bildirilmiştir. Çalışmada da, azot dozlarının, bitki boyu üzerinde pozitif yönlü bir etki gösterdiği ve
ÇOPUL S, GENÇSOYLU i uygulanan azot dozu miktarı arttıkça, bitki boyu değerlerinin de arttığı belirlenmiştir.

Koza sayısı değerleri, azot dozları bakımından incelendiğinde; tüm azot dozlarında, en yüksek koza sayıları, Özbek 105 ve Lydia'da; en düşük koza sayıları Julia pamuk çeşidinde saptanmıştır. Koza sayısı değerleri, pamuk çeşitleri bakımından incelendiğinde ise tüm pamuk çeşitlerinde en yüksek bitki koza sayıları, 140 ve 210 kg $\mathrm{N} /$ ha dozlarında, en düşük bitki koza sayıları ise $0 \mathrm{~kg} \mathrm{~N} / \mathrm{ha}$ dozunda tespit edilmiştir (Çizelge 7).

Ge ve ark. (2003), Toklu (2003), Gadhiya ve ark. (2009), Yolcu (2009), Bibi ve ark. (2011), Hakoomat ve Raheel (2011), Durkal (2017) ve Win ve ark. (2017) tarafından yürütülmüş önceki çalışmalardan elde edilen sonuçlara benzer şekilde çalışmada da, azot dozları ile koza sayısı değerleri arasında pozitif yönlü bir ilişki olduğu ve uygulanan azot dozu miktarı arttıkça, koza sayısı değerlerinin de arttığı belirlenmiştir.

Pamuk çeşitlerinde farklı azot dozlarında tespit edilen bazı lif kalite özelliklerine ilişkin varyans analizi sonuçlarına göre; lif inceliği, lif uzunluğu, lif kopma dayanıklılığı ve üniformite indeksi bakımından yıl, çeşit, azot dozları ve yıl x azot dozları interaksiyonu arasındaki farkın istatistiksel açıdan önemli düzeyde olduğu saptanmıştır (Çizelge 8).

Çizelge 6. Farklı azot dozları ve pamuk çeşitlerinde ortalama bitki boyu değerleri*

\begin{tabular}{llllll}
\hline $\begin{array}{l}\text { Azot Dozları } \\
\text { (kg N/ha) }\end{array}$ & Özbek105 & Gloria & Julia & Lydia & Azot Dozları Ort. \\
\hline $\mathbf{0}$ & $85.32 \mathrm{Ad}$ & $83.48 \mathrm{Ac}$ & $75.65 \mathrm{Bc}$ & $85.10 \mathrm{Ad}$ & $82.39 \mathrm{~d}$ \\
$\mathbf{7 0}$ & $95.23 \mathrm{Ac}$ & $94.45 \mathrm{Ab}$ & $86.52 \mathrm{Bb}$ & $94.78 \mathrm{Ac}$ & $92.75 \mathrm{c}$ \\
$\mathbf{1 4 0}$ & $104.88 \mathrm{Ab}$ & $101.79 \mathrm{Aa}$ & $95.78 \mathrm{Ba}$ & $103.56 \mathrm{Ab}$ & $101.20 \mathrm{~b}$ \\
$\mathbf{2 1 0}$ & $109.18 \mathrm{Aa}$ & $105.71 \mathrm{Ba}$ & $99.18 \mathrm{Ca}$ & $110.04 \mathrm{Aa}$ & $106.03 \mathrm{a}$ \\
Çeşit Ort. & $98.65 \mathrm{~A}$ & $96.36 \mathrm{~B}$ & $89.28 \mathrm{C}$ & $98.37 \mathrm{~A}$ & \\
LSD & & & & \\
\hline
\end{tabular}

*iki yılın ortalama değerleri alınmıştır. Aynı harfle gösterilen ortalamalar arasında, LSD testine göre $(p<0.05)$ istatistiksel olarak fark yoktur. Küçük harfler, aynı sütundaki ortalamalar arasındaki farklılıkları göstermektedir $(p<0.05)$.

Büyük harfler, aynı satırdaki ortalamalar arasındaki farklııkları göstermektedir $(p<0.05)$.

Çizelge 7. Farklı azot dozları ve pamuk çeşitlerinde ortalama koza sayısı değerleri *

\begin{tabular}{llllll}
\hline $\begin{array}{l}\text { Azot Dozları } \\
\text { (kg N/ha) }\end{array}$ & Özbek105 & Gloria & Julia & Lydia & Azot Dozları Ort. \\
\hline $\mathbf{0}$ & $8.77 \mathrm{Ab}$ & $7.94 \mathrm{Bb}$ & $6.97 \mathrm{Cb}$ & $8.95 \mathrm{Ab}$ & $8.16 \mathrm{~d}$ \\
$\mathbf{7 0}$ & $10.62 \mathrm{Aab}$ & $9.73 \mathrm{Bab}$ & $8.34 \mathrm{Cab}$ & $10.71 \mathrm{Aab}$ & $9.85 \mathrm{C}$ \\
$\mathbf{1 4 0}$ & $12.46 \mathrm{Aa}$ & $11.48 \mathrm{Ba}$ & $9.94 \mathrm{Cab}$ & $12.27 \mathrm{Aab}$ & $11.54 \mathrm{~b}$ \\
$\mathbf{2 1 0}$ & $13.05 \mathrm{Aa}$ & $12.11 \mathrm{Ba}$ & $10.66 \mathrm{Ca}$ & $12.65 \mathrm{Aa}$ & $12.12 \mathrm{a}$ \\
Çeşit Ort. & $11.22 \mathrm{~A}$ & $10.32 \mathrm{~B}$ & $8.98 \mathrm{C}$ & $11.15 \mathrm{~A}$ & \\
LSD & & & & \\
\hline
\end{tabular}

*iki yılın ortalama değerleri alınmıştır. Aynı harfle gösterilen ortalamalar arasında, LSD testine göre ( $p<0.05)$ istatistiksel olarak fark yoktur. Küçük harfler, aynı sütundaki ortalamalar arasındaki farklııkları göstermektedir $(p<0.05)$.

Büyük harfler, aynı satırdaki ortalamalar arasındaki farklıııkları göstermektedir $(p<0.05)$. 
Lif inceliği değerleri bakımından; 0, 140, $210 \mathrm{~kg} \mathrm{~N} / \mathrm{ha}$ azot dozlarında, pamuk çeşitleri arasındaki fark, istatistiksel açıdan önemsiz bulunmuştur. $70 \mathrm{~kg} \mathrm{~N} / \mathrm{ha}$ azot dozunda ise en ince lif değeri, Julia; en kalın lif değeri Özbek 105 pamuk çeşitlerinde tespit edilmiştir. Lif inceliği değerleri bakımından, Özbek 105 pamuk çeşidinde, azot dozları arasındaki fark, istatistiksel açıdan önemsiz bulunmuştur. Gloria, Julia ve Lydia pamuk çeşitlerinde, en ince lif değerleri, $140 \mathrm{~kg} \mathrm{~N} / \mathrm{ha}$ azot dozunda; en kalın lif değerleri 0 kg N/ha azot dozunda saptanmıştır (Çizelge 9).

Azot dozu miktarındaki artış ile birlikte lif inceliği değerleri de $140 \mathrm{~kg} \mathrm{~N} /$ ha azot dozuna kadar artmıştır. Çalışmadan elde edilen bu sonuçlar; Işık (2009), Yolcu (2009) ve Win ve ark. (2017) tarafından yapılan çalışmalardan elde edilen sonuçlar ile benzerlik göstermiştir.

Lif uzunluğu değerleri, azot dozları bakımından incelendiğinde; tüm azot dozlarında, en yüksek lif uzunluğu değerleri, Lydia ve Gloria'da; en düşük lif uzunluğu değerleri ise Özbek 105 pamuk çeşidinde belirlenmiştir. Lif uzunluğu değerleri, pamuk çeşitleri bakımından incelendiğinde ise Özbek 105, Gloria, Julia ve Lydia pamuk çeşitlerinde, en uzun lif uzunluğu değerleri, $140 \mathrm{~kg} \mathrm{~N} / \mathrm{ha}$ azot dozunda; en kısa lif uzunluğu değerleri ise $0 \mathrm{~kg} \mathrm{~N} / \mathrm{ha}$ azot dozunda saptanmıştır (Çizelge 10). Karademir ve ark. (2005), Yolcu (2009), Sui ve ark. (2017), Win ve ark. (2017) tarafından yürütülmüş önceki çalışmalarda, uygulanan azotun, lif uzunluğunu az da olsa arttırdığı bildirilmiştir. Çalışmada da uygulanan azot dozu miktarındaki artış ile birlikte lif uzunluğu değerlerinin, belirli bir azot dozuna (140 kg N/ha) kadar arttığı, bu azot dozunun üzerinde uygulanan azot dozlarında (210 kg N/ha) ise lif uzunluğu değerlerinin azaldığı belirlenmiştir.

Lif kopma dayanıklılığı değerleri, azot dozları bakımından incelendiğinde; 0, 70, 140 ve $210 \mathrm{~kg} \mathrm{~N}$ /ha azot dozları bakımından en yüksek lif kopma dayanıklılığı; Gloria ve Lydia'da; en düşük lif kopma dayanıklılığı ise Özbek 105'te belirlenmiştir. Lif kopma dayanıklılığı değerleri, pamuk çeşitleri bakımından incelendiğinde; Özbek 105 pamuk çeşidinde, en yüksek lif kopma dayanıklılığı, $140 \mathrm{~kg} \mathrm{~N} / \mathrm{ha}$ dozunda; en düşük lif kopma dayanıklılığı ise $0 \mathrm{~kg} \mathrm{~N} / \mathrm{ha}$ dozunda saptanmıştır. Gloria, Julia ve Lydia pamuk çeşitlerinde, azot dozları arasındaki farkın, istatistiksel açıdan önemli düzeyde ( $p>0.05)$ olmadığı belirlenmiştir (Çizelge 11).

Çizelge 8. Pamuk çeşitlerinde farklı azot dozlarında tespit edilen bazı lif kalite özelliklerine ilişkin varyans analizi sonuçları

\begin{tabular}{llllll}
\hline Varyasyon Kaynağı & SD & Lif İnceliği & Lif Uzunluğu & Lif Kopma Dayanıklılı̆ı & Üniformite İndeksi \\
\hline Yıl & 1 & $4.918032^{*}$ & $4.56398^{*}$ & $89.11125^{*}$ & $7.80125^{*}$ \\
Tekerrür [Yıl] & 6 & 0.054237 & 0.503117 & 7.241667 & 0.386458 \\
Çeşit & 3 & $0.540736^{*}$ & $35.48353^{*}$ & $252.7727^{*}$ & $10.46313^{*}$ \\
Yıl x Çeşit & 3 & $0.238397^{*}$ & 0.957167 & 6.07354 & 1.100625 \\
Azot Dozları & 3 & $0.999861^{*}$ & $7.02191^{*}$ & $11.66771^{*}$ & $7.712292^{*}$ \\
Yıl x Azot Dozları & 3 & $0.546355^{*}$ & $5.620367^{*}$ & $9.989377^{*}$ & $5.207708^{*}$ \\
Çeşit x Azot Dozları & 9 & 0.041929 & 0.245753 & 2.537083 & 0.988611 \\
Yıl x Çeşit x Azot Dozları & 9 & 0.052661 & 0.564357 & 4.543889 & 1.054306 \\
Hata & 90 & 0.072277 & 0.76613 & 2.9289 & 1.20657 \\
CV (\%) & & 5.36 & 2.89 & 4.94 & 1.28 \\
\hline
\end{tabular}

$\left({ }^{*}\right)$ : 0.05 düzeyinde önemli fark bulunmaktadır.

Çizelge 9. Farklı azot dozları ve pamuk çeşitlerinde ortalama lif inceliği değerleri *

\begin{tabular}{llllll}
\hline $\begin{array}{l}\text { Azot Dozları } \\
\text { (kg N/ha) }\end{array}$ & Özbek105 & Gloria & $\begin{array}{c}\text { Çeşitler } \\
\text { Julia }\end{array}$ & Lydia & Azot Dozları Ort. \\
\hline $\mathbf{0}$ & $8.77 \mathrm{Ab}$ & $7.94 \mathrm{Bb}$ & $6.97 \mathrm{Cb}$ & $8.95 \mathrm{Ab}$ & $8.16 \mathrm{~d}$ \\
$\mathbf{7 0}$ & $10.62 \mathrm{Aab}$ & $9.73 \mathrm{Bab}$ & $8.34 \mathrm{Cab}$ & $10.71 \mathrm{Aab}$ & $9.85 \mathrm{c}$ \\
$\mathbf{1 4 0}$ & $12.46 \mathrm{Aa}$ & $11.48 \mathrm{Ba}$ & $9.94 \mathrm{Cab}$ & $12.27 \mathrm{Aab}$ & $1.54 \mathrm{~b}$ \\
$\mathbf{2 1 0}$ & $13.05 \mathrm{Aa}$ & $12.11 \mathrm{Ba}$ & $10.66 \mathrm{Ca}$ & $12.65 \mathrm{Aa}$ & $12.12 \mathrm{a}$ \\
Çeşit Ort. & $11.22 \mathrm{~A}$ & $10.32 \mathrm{~B}$ & $8.98 \mathrm{C}$ & $11.15 \mathrm{~A}$ & \\
LSD & & & & \\
\hline
\end{tabular}

*iki yılın ortalama değerleri alınmıştır. Aynı harfle gösterilen ortalamalar arasında, LSD testine göre ( $p<0.05)$ istatistiksel olarak fark yoktur. Küçük harfler, aynı sütundaki ortalamalar arasındaki farklılıkları göstermektedir $(p<0.05)$.

Büyük harfler, aynı satırdaki ortalamalar arasındaki farklılıkları göstermektedir $(p<0.05)$. 
Çizelge 10. Farklı azot dozları ve pamuk çeşitlerinde ortalama lif uzunluğu değerleri*

\begin{tabular}{llllll}
\hline $\begin{array}{l}\text { Azot Dozları } \\
\text { (kg N/ha) }\end{array}$ & Özbek105 & Gloria & $\begin{array}{c}\text { Çeşitler } \\
\text { Julia }\end{array}$ & Lydia & Azot Dozları Ort. \\
\hline $\mathbf{0}$ & $27.99 \mathrm{Bb}$ & $29.96 \mathrm{Ab}$ & $29.85 \mathrm{Ab}$ & $30.51 \mathrm{Ab}$ & $29.58 \mathrm{~b}$ \\
$\mathbf{7 0}$ & $28.90 \mathrm{Ba}$ & $31.12 \mathrm{Aab}$ & $30.61 \mathrm{Aab}$ & $30.98 \mathrm{Aab}$ & $30.40 \mathrm{a}$ \\
$\mathbf{1 4 0}$ & $29.09 \mathrm{Ba}$ & $30.96 \mathrm{Aab}$ & $31.11 \mathrm{Aa}$ & $31.30 \mathrm{Aa}$ & $30.61 \mathrm{a}$ \\
$\mathbf{2 1 0}$ & $28.84 \mathrm{Bab}$ & $31.22 \mathrm{Aa}$ & $30.81 \mathrm{Aab}$ & $31.05 \mathrm{Aab}$ & $30.48 \mathrm{a}$ \\
Çeşit Ort. & $28.70 \mathrm{~B}$ & $30.81 \mathrm{~A}$ & $30.59 \mathrm{~A}$ & $30.96 \mathrm{~A}$ & \\
LSD $_{(0,05)}$ & 0.87 & & & & \\
\hline
\end{tabular}

*íki yılın ortalama değerleri alınmıştır. Aynı harfle gösterilen ortalamalar arasında, LSD testine göre ( $p<0.05)$ istatistiksel olarak fark yoktur. Küçük harfler, aynı sütundaki ortalamalar arasındaki farklılıkları göstermektedir $(p<0.05)$.

Büyük harfler, aynı satırdaki ortalamalar arasındaki farklııkları göstermektedir $(p<0.05)$.

Çizelge 11. Farklı azot dozları ve pamuk çeşitlerinde ortalama lif kopma dayanıklılığı değerleri *

\begin{tabular}{lllllc}
\hline $\begin{array}{l}\text { Azot Dozları } \\
\text { (kg N/ha) }\end{array}$ & Özbek105 & Gloria & $\begin{array}{c}\text { Çeşitler } \\
\text { Julia }\end{array}$ & Lydia & Azot Dozları Ort. \\
\hline $\mathbf{0}$ & $29.06 \mathrm{Cb}$ & $35.83 \mathrm{ABa}$ & $34.35 \mathrm{Ba}$ & $36.34 \mathrm{Aa}$ & $33.89 \mathrm{~b}$ \\
$\mathbf{7 0}$ & $31.11 \mathrm{Ba}$ & $36.64 \mathrm{Aa}$ & $35.26 \mathrm{Aa}$ & $36.83 \mathrm{Aa}$ & $34.96 \mathrm{a}$ \\
$\mathbf{1 4 0}$ & $31.48 \mathrm{Ca}$ & $37.61 \mathrm{Aa}$ & $34.68 \mathrm{Ba}$ & $37.30 \mathrm{Aa}$ & $35.27 \mathrm{a}$ \\
$\mathbf{2 1 0}$ & $30.75 \mathrm{Ba}$ & $36.31 \mathrm{Aa}$ & $35.08 \mathrm{Aa}$ & $35.59 \mathrm{Aa}$ & $34.43 \mathrm{ab}$ \\
Çeşit Ort. & $30.60 \mathrm{C}$ & $36.60 \mathrm{~A}$ & $34.84 \mathrm{~B}$ & $36.51 \mathrm{~A}$ & \\
LSD $_{(0,05)}$ & 1.70 & & & & \\
\hline
\end{tabular}

*iki yılın ortalama değerleri alınmıştır. Aynı harfle gösterilen ortalamalar arasında, LSD testine göre ( $p<0.05$ ) istatistiksel olarak fark yoktur. Küçük harfler, aynı sütundaki ortalamalar arasındaki farklılıkları göstermektedir $(p<0.05)$.

Büyük harfler, aynı satırdaki ortalamalar arasındaki farklılıkları göstermektedir $(p<0.05)$.

Toklu (2003), Karademir ve ark. (2005), Işık (2009), Yolcu (2009), Hakoomat ve Raheel (2011) ve Cevheri (2016) tarafından yürütülmüş önceki çalışmalarda, azot dozlarının lif kopma dayanıklılı̆ı üzerinde istatistiksel açıdan önemli bir etkisinin olmadığı saptanmıştır. Çalışmada da, iki yıllık ortalama lif kopma dayanıklılığı değerlerine göre, Gloria, Julia ve Lydia pamuk çeşitlerinde, azot dozlarının, lif kopma dayanıklıı̆ı üzerindeki etkisinin istatistiksel açıdan önemli düzeyde olmadığı belirlenmiştir.

Üniformite indeksi değerleri, azot dozları bakımından incelendiğinde; 0 ve $140 \mathrm{~kg} \mathrm{~N} / \mathrm{ha}$ azot dozlarında, en yüksek üniformite indeksi değeri Lydia; en düşük üniformite indeksi ise Özbek 105 pamuk çeşidinde tespit edilmiştir. 70

Çizelge 12. Farklı azot dozları ve pamuk çeşitlerinde ortalama üniformite indeksi değerleri*

\begin{tabular}{|c|c|c|c|c|c|}
\hline \multirow{2}{*}{$\begin{array}{l}\text { Azot Dozları } \\
\text { (kg N/ha) }\end{array}$} & \multicolumn{4}{|c|}{ Çeşitler } & \multirow{2}{*}{ Azot Dozları Ort. } \\
\hline & Özbek105 & Gloria & Julia & Lydia & \\
\hline 0 & $84.04 \mathrm{Bb}$ & $85.85 \mathrm{Aa}$ & $85.18 \mathrm{ABb}$ & $86.20 \mathrm{Aa}$ & $85.32 \mathrm{~b}$ \\
\hline 70 & $85.99 \mathrm{Aa}$ & $86.38 \mathrm{Aa}$ & 86.05Aab & $86.66 \mathrm{Aa}$ & $86.27 \mathrm{a}$ \\
\hline 140 & $85.56 \mathrm{Ba}$ & 86.38ABa & $86.85 \mathrm{Aa}$ & 86.79ABa & 86.39 a \\
\hline 210 & $85.36 \mathrm{Aa}$ & $86.40 \mathrm{Aa}$ & 86.31Aab & $86.66 \mathrm{Aa}$ & 86.18 a \\
\hline Çeşit Ort. & $85.24 \mathrm{~B}$ & $86.25 \mathrm{~A}$ & $86.10 \mathrm{~A}$ & $86.58 \mathrm{~A}$ & \\
\hline $\operatorname{LSD}_{(0,05)}$ & 1.09 & & & & \\
\hline
\end{tabular}

*iki yılın ortalama değerleri alınmıştır. Aynı harfle gösterilen ortalamalar arasında, LSD testine göre $(p<0.05)$ istatistiksel olarak fark yoktur. Küçük harfler, aynı sütundaki ortalamalar arasındaki farklılıkları göstermektedir $(p<0.05)$.

Büyük harfler, aynı satırdaki ortalamalar arasındaki farklılıkları göstermektedir $(p<0.05)$. 
azot dozlarının üniformite indeksi üzerinde istatistiksel açıdan önemli bir etkisinin olmadığı bildirilmiştir. Çalışmada da, azot dozlarının, üniformite indeksi (\%) üzerindeki etkisinin istatistiksel açıdan önemli düzeyde olmadığı tespit edilmiştir.

\section{SONUÇ}

Çalışmada; kütlü pamuk verimi, çırçır randımanı,100 tohum ağılığı, bitki boyu, koza sayısı, lif inceliği, lif uzunluğu, lif kopma dayanıklılığı ve üniformite indeksi incelenmiştir. Azot dozu miktarındaki artışın, kütlü pamuk verimini belirli bir noktaya kadar arttırdığı belirlenmiştir. Ayrıca, pamuk üretiminde ekolojik ve ekonomik açıdan uygulanması gereken en ideal azot dozunun, $150 \mathrm{~kg} \mathrm{~N} / \mathrm{ha}$ olduğu tespit edilmiştir.

Azot dozu miktarındaki artış ile 100 tohum ağırlığı (g), bitki boyu $(\mathrm{cm})$, koza sayısı (adet/bitki), lif inceliği (mic) ve lif uzunluğu (mm) değerlerinin arttığı; çırçır randımanının (\%) ise azaldığı belirlenmiştir. Ayrıca, azot dozlarının, lif kopma dayanıklılığı ve üniformite indeksi değerleri üzerinde ise istatistiksel açıdan önemli bir etkisinin olmadığı tespit edilmiştir.

Pamuk tarımının ekolojik ve ekonomik sürdürülebilirliği açısından gübrelemenin, dengeli ve önerilen dozlarda yapılması önemlidir. Ayrıca, azotlu gübrelerin gereğinden fazla kullanılması, çevre kirliliğine de neden olmaktadır. Bu nedenlerden dolayı, ekonomik bir pamuk üretiminin yapılabilmesi ve çevre kirliliğinin önlenmesi amacıyla aşırı dozda azotlu gübre kullanımından kaçınılması, azotlu gübrelerin dengeli ve önerilen dozlarda uygulanması önerilmektedir.

\section{TEŞEKKÜR}

Doktora tezimin bir kısmı olan bu çalışmada, Aydın Adnan Menderes Üniversitesi Bilimsel Araştırma Projeleri Komisyonuna (ZRF-15072) ve T.C. Tarım ve Orman Bakanlığı'na bağlı olan Tarımsal Araştırmalar ve Politikalar Genel Müdürlüğü'ne desteklerinden dolayı teşekkür ederim.

\section{KAYNAKLAR}

Altınkaya R (2009) Farklı Pix ve Azot Dozlarının Pamukta (Gossypium hirsutum L.) Verim, Verim Komponentleri ve Lif Kalite Özellikleri Üzerine Etkisi. Yüksek Lisans Tezi, Aydın Adnan Menderes Üniversitesi, Aydın.

Anonim (2018) Türkiye İstatistik Kurumu, Erişim Linki: http://biruni.tuik.gov.tr (Erişim tarihi: 26.11.2018).

Anusha S, Prasada Rao G M V, Sai Ram Kumar D V (2017) Influence of different nitrogen levels on the management of Bt cotton sucking pests. Journal of Entomology and Zoology Studies, 5(2): 16-21.

Aydemir M (1968) Azot ve su gelişim faktörlerinin pamuk verimine etkileri. 1968 Yılı Faaliyet Raporu, Pamuk Araştırma Enstitüsü Müdürlüğü, Aydın.

Berberoğlu F, Karaltın S (2001) Farklı azot ve fosfor dozlarının Maraş-92 pamuk çeşidinde (Gossypium hirsutum L.) verim ve fizyolojik özelliklere etkisi. Türkiye 4. Tarla Bitkileri Kongresi Bildirileri, Cilt II., 1721 Eylül 2001, Erzurum, 345-349.
Berger J (1969) The World's major fibre crops their cultivation and manuring. Zurich, 216-222.

Bibi Z, Khan N, Mussarat M, Khan M J, Ahmad R, Khan I U, Shahen S (2011) Response of Gossypium hirsutum genotypes to various nitrogen levels. Pakistan Journal of Botany, 43(5): 2403-2409.

Bondada B R, Oosterhuis D, Wullschleger S D, Harris W M (1994) Anatomical considerations related to photosynthesis in cotton leaves, bracts, and the capsule wall. Journal of Experimental Botany, 45(1): 111-118.

Boquet D J, Moser E B, Breitenbeck G A (1993) Nitrogen effects on boll production of field-grown cotton. Agronomy Journal, 85: 34-39.

Cevheri C i (2016) Harran Ovası Organik Üretim Koşullarında Organik ve Mikrobiyal Gübre Uygulamalarının Bazı Pamuk Çeşitlerinde (Gossypium hirsutum L.) Tarımsal ve Lif Kalite Özellikleri Üzerine Etkisi. Doktora Tezi, Harran Üniversitesi, Şanlıurfa.

Durkal Ö (2017) Organik Olarak Yetiştirilen Pamuk Çeşitlerinin Azot Gereksiniminin Belirlenmesi. Yüksek Lisans Tezi, Mustafa Kemal Üniversitesi, Hatay.

El-Dababi A S, Hammam G Y, Nagib M A (1995) Effect of planting date, $\mathrm{N}$ and $\mathrm{P}$ application levels on seed index, lint percentage and technological characters of Giza 80 cotton cultivars. Annals of Agricultural Science, 33(2): 455-464.

Emiroğlu Ş H (1970) Değişik Sulama, Gübreleme ve Ekim Mesafesi Şartları Altında Coker Pamuğunun Verimle Illgili Bazı Vasıfları Üzerinde Araştırmalar. Ege Üniversitesi Ziraat Fakültesi Yayınları, No:157, İzmir.

Fritschi F B, Roberts B A, Travis R L, Rains D W, Hutcmacher R B (2003) Response of irrigated Acala and Pima cotton to nitrogen fertilization: growth, dry matter partitioning and yield. Agronomy Journal, 95: 133146.

Gadhiya S S, Patel B B, Jadav N J, Pavaya R P, Patel M V, Patel V R (2009) Effect of different levels of nitrogen, phosphorus and potassium on growth, yield and quality of Bt cotton. Department of Agricultural Chemistry and Soil Science, C.P. College of Agriculture, S. D. Agricultural University, Sardarkrushinagar (Gujarat), India, 37-42.

Ge F, Liu X, Li H, Men X, Su J (2003) Effect of nitrogen fertilizer on pest population and cotton (Gossypium hirsutum L.) production. The Journal of Applied Ecology, 14(10): 1735-1738.

Gerik T J, Faver K L, Thaxton P M, El-Zik K M (1996) Late season water stress in cotton: I. plant growth, water use, and yield. Crop Science, 36: 914-921.

Hakoomat A, Raheel A H (2011) Growth, yield and yield components of American cotton as affected by cultivars and nitrogen fertilizer. International Journal of Scientific \& Engineering Research, 2: 112.

Işık F, Gençsoylu i (2009) Pamukta (Gossypium hirsutum L.) uygulanan bazı yaprak gübrelerinin zararlılar, doğal düşmanlar, verim ve lif kalitesi üzerine etkileri. 
Türkiye III. Bitki Koruma Kongresi Bildirileri, 15-18.08.2009, Van, 123.

Jackson M L (1967) Soil Chemical Analysis. Prentice Hall of Idia Private Limited, India, 498.

Karademir Ç, Karademir E, Doran i, Altıkat A (2005) Diyarbakır ekolojik koşullarında farklı azot ve fosfor uygulamalarının pamukta verim ve lif teknolojik özelliklere etkisi. Gaziosmanpaşa Üniversitesi Ziraat Fakültesi Dergisi, 22(1): 55-61.

Kılıç Y (2008) Mardin/Derik Ekolojik Koşullarında İkinci Ürün Olarak Yetiştirilebilecek Pamuk (Gossypium hirsutum L.) Çeşitlerinin Tarımsal ve Teknolojik Özellikleri ve Bunlar Arasındaki İlişkilerin Belirlenmesi Üzerinde Bir Araştırma. Yüksek Lisans Tezi, Çukurova Üniversitesi, Adana.

Li P, Dong $H$, Zheng C, Sun M, Liu A, Wang G, Liu S, Zhang S, Chen J, Li Y, Pang C, Zhao $X$ (2017) Optimizing nitrogen application rate and plant density for improving cotton yield and nitrogen use efficiency in the North China Plain. Plos One, 1-15.

Mart C (2005) Pamukta Entegre Üretim. Kahramanmaraş Sütçü İmam Üniversitesi Yayınları; 119: 93.

Parajulee M, Carroll S, Hakeem A (2016) Influence of nitrogen fertilizer on cotton host-plant quality and its impact on cotton aphids. Beltwide Cotton Production Research Conferences, 5-7 January, 2016, New Orleans, USA.

Radin J W, Mauney J R (1986) The nitrogen stress syndrome. Cotton Physiology, 91-105.

Sui R, Byler R K, Delhom C D (2017) Effect of nitrogen application rates on yield and quality in irrigated and
ÇOPUL S, GENÇSOYLU i rainfed cotton. The Journal of Cotton Science, 21: 113-121.

Şahin A, Kıvılcım N, Hüyük O (1994) Nazilli M-503 pamuk çeşidinin azot gereksinimi. Nazilli Pamuk Araştırma Enstitüsü Müdürlüğü 1994 Yılı Pamuk Araştırma Proje ve Sonuçları, Aydın.

Şenel M (1980) Pamuk Islahı, Yetiştirilmesi ve Teknolojisi. Tarım Bakanlığı Bölge Pamuk Araştırma Enstitüsü Müdürlüğü. Yayın No. 36, Adana.

Toklu P (2003) Pamukta (Gossypium hirsutum L.) Azot Kullanım Etkinliğinin Damlama Sulama ve Salma Sulama Yöntemleri Yönünden Karşılaştırılması Üzerine Bir Araştırma. Doktora Tezi, Çukurova Üniversitesi, Adana.

Weir B L, Kerby T A, Hake K D, Roberts B A, Zelinski L J (1996) Cotton fertility. In: Hake, S.J., Kerby, T.A., Hake, K.D. (Eds.), Cotton Production Manual. Beltwide Cotton Production Research Conferences, 9-12 January 1996, University of California, CA, U.S.A, 210227.

Win T Z, Myint A K, Ngwe K, Thein S S, Khaing T T (2017) Effects of nitrogen and potassium application on plant growth, yield and fiber quality of cotton (Gossypium hirsutum L.). Journal of Agricultural Research 4(1): 4755.

Yolcu S (2009) Pamukta (Gossypium hirsutum L.) Farklı Azot Doz ve Uygulama Zamanlarının Verim ve Verim Unsurları ile Bitki Büyüme ve Gelişmesini İzleme Parametrelerine Etkisi. Doktora Tezi, Kahramanmaraş Sütçü İmam Üniversitesi, Kahramanmaraş. 
